\title{
Migrantes russófonos no Brasil no século XXI: perfis demográficos, caminhos de inserção e projetos migratórios
}

\author{
Russian-speaking migrants in Brazil in the 21st \\ century: demographic profiles, insertion paths \\ and migratory projects
}

Anna Smirnova Henriques ${ }^{1}$

Svetlana Ruseishvili

Resumo: O presente artigo oferece um breve panorama das migrações russófonas contemporâneas no Brasil. Com base nos dados do SISMIGRA, consolidados no Banco Interativo do Observatório das Migrações em São Paulo, e no corpus de 40 entrevistas semiestruturadas com migrantes russófonos residentes no Brasil, o texto busca traçar o perfil demográfico de migrantes russófonos e os modos de sua inserção socioeconômica. Para isso, mobiliza-se a noção do "espaço social russófono", contemplando a heterogeneidade dos perfis de migrantes pós-soviéticos. Por fim, discutem-se dificuldades de acesso de migrantes à instrução formal em português como língua estrangeira, com destaque ao Celpe-Bras como um entrave na aquisição da cidadania brasileira, um dos pontos centrais em projetos migratórios de russófonos no Brasil.

Palavras-chave: migração; russófonos; Celpe-Bras; naturalização.

\footnotetext{
${ }^{1}$ Doutora em Ciências pela UNIFESP, atualmente pós-doutoranda no Laboratório Integrado de Análise Acústica e Cognição/ LIAAC, Programa de Estudos Pós-Graduados/ PEPG em Linguística Aplicada e Estudos da Linguagem/LAEL, Pontifícia Universidade Católica de São Paulo/PUC-SP, Brasil. ORCID: https://orcid.org/0000-0003-3011-372X. E-mail: palestrasrussas@gmail.com..

${ }^{2}$ Doutora em Sociologia pela USP, atualmente professora do Departamento de Sociologia, Universidade Federal de São Carlos/UFSCar, Brasil. ORCID: https://orcid.org/0000-0001-8170-9692. E-mail: $\underline{\text { s.ruseish- }}$ vili@gmail.com.
} 
Abstract: The current work presents a brief panorama of contemporary Russophone migration flows to Brazil. Based on the data of SISMIGRA (Brazilian system of migrant registration), available in the Interactive Bank developed by Observatory of Migration in São Paulo, and the corpus of 40 semi-structured interviews with Russophone migrants living in Brazil, the text seeks to trace the demographic profile of these migrants and the ways of their socioeconomic insertion. The notion of the "Russian-speaking social space" is mobilized in order to consider the heterogeneity of the profiles of post-Soviet migrants. Finally, we discuss the difficulties faced by migrants to obtain the formal instruction in Portuguese as a Foreign Language, with emphasis on the Celpe-Bras proficiency test as an obstacle to the acquisition of Brazilian citizenship, one of the central aims of the migration projects of Russophones in Brazil.

Keywords: migration; Russophones; Celpe-Bras; naturalization.

\section{INTRODUÇÃO}

A imigração russa no Brasil é um tema ainda pouco pesquisado nas ciências humanas, com enfoque nos estudos migratórios. Ao longo do século XX, a pesquisa social brasileira teve como principal interesse aqueles grupos dos migrantes que contribuíram para a transição da economia escravocrata para a baseada em trabalho assalariado, com destaque para os grupos vindos da Europa ou do Oriente Médio (Fausto, 1991; Seyferth, 2014). Nesse sentido, os russos não formavam comunidades étnicas localizadas nem no campo, nem nas cidades, não tiveram protagonismo no movimento operário e nem reivindicavam a sua presença no espaço urbano. Além disso, o discurso anti-comunista persistente no Brasil no século XX obrigou-os a uma auto-retirada do espaço público, independentemente de suas posições políticas (Ruseishvili, 2016). Com o tempo, o perfil dos imigrantes no Brasil havia se modificado; nos últimos anos, os fluxos Sul-Sul, caribenhos e Sul-Norte tem tido destaque nos estudos migratórios (Baeninger, 2018). No século XXI, mesmo considerando o fim da URSS e da ditadura civil-militar no Brasil, os novos migrantes do espaço pós-soviético continuaram sem destaque nas pesquisas das migrações.

Para suprir essa lacuna, o presente artigo oferece um breve panorama das migrações russófonas contemporâneas. Na primeira seção, buscamos oferecer uma definição das migrações pós-soviéticas, recorrendo à noção do "espaço social russófono" ou "migrações russófonas". Na segunda seção, apresentamos um breve histórico da presença dos migrantes russófonos no Brasil, destacando a heterogeneidade de suas origens, de seus projetos e trajetórias migratórias. Em seguida, buscamos estimar a população migrante russófona no Brasil contemporâneo, com base nos dados do Sistema de Registro Nacional Migratório (SISMIGRA), consolidados pelo Banco Interativo do Observatório das Migrações em São Paulo (SISMIGRA, Banco Interativo, 2020). Com base nesses dados, traçamos alguns perfis de migrantes russófonos no país e sua inserção socioeconômica e espacial. Por fim, com base em dados obtidos através da aplicação de questionários em nossos experimentos anteriores (Smirnova Henriques et al., 2019; Smirnova Henriques et al., no prelo) e por meio da realização de cerca de 40 entrevistas semiestruturadas coletadas para a construção do nosso banco de russófonos de São Paulo (Smirnova Henriques et 
al., no prelo), buscamos descrever as dificuldades desses migrantes no acesso à instrução formal em português como língua estrangeira. Discutimos como a aquisição do idioma português e a exigência do certificado Celpe-Bras interferiu no ponto central dos projetos migratórios dos russófonos no Brasil: a aquisição da cidadania brasileira.

\section{MIGRAÇÕES RUSSÓFONAS: A DEFINIÇÃO DO TERMO, CAUSAS E DESTINOS}

O termo "russófono" pode ser definido de duas maneiras: ele pode incluir qualquer indivíduo que domine o idioma russo ou, conforme consolidado no meio acadêmico nas últimas décadas, apenas os falantes de russo dos estados pós-soviéticos (Panarin, 1999). Estes podem ser subdivididos em três grupos: (1) russos étnicos residentes dentro e fora da Federação Russa; (2) falantes de russo que etnicamente não se consideram russos e que residem fora do estado que representa a sua etnia (por exemplo, alemães, coreanos, ucranianos, judeus ou armênios residentes na Rússia); (3) falantes de russo que etnicamente não se consideram russos, mas, mesmo morando na sua área étnica, fazem o uso preferencial da língua russa e frequentemente não dominam a língua natal da sua etnia (os exemplos comuns são a Ucrânia e o Cazaquistão).

Entre esses, o grupo de russos étnicos é o mais numeroso. O colapso da União Soviética em 1991 deixou 25 milhões de russos étnicos (17,5\% da população da Rússia naquele momento) nos territórios de novos países independentes, transformando-os em migrantes sem nunca terem deixado as suas casas (Tertri, 2017). Atualmente, os países que possuem as maiores comunidades russófonas fora da Rússia são Ucrânia (29 milhões, 68\% da população), Cazaquistão (15 milhões, 85\% da população), Uzbequistão (12 milhões, $41 \%$ da população) e Belarus (7 milhões, 72\% da população) (Zhou; Koloda, 2019).

Além dessa "emigração involuntária" por causa da mudança de fronteiras, o fim da União Soviética também provocou uma onda de emigração, tanto da Rússia quanto de outros países ex-soviéticos, para os países onde o russo não era o idioma dominante e as condições econômicas eram melhores. Sem considerar a Europa do Leste e o espaço pós-soviético, os países que atualmente possuem as maiores comunidades russófonas são Alemanha (5,4 milhões, 5\% da população), EUA (3,5 milhões, $1 \%$ da população), Israel (1 milhão, 20\% da população) e França (0,5 milhões, 0,75\% da população) (Zhou; Koloda, 2019). Os países da América Latina são reconhecidos como um destino importante da emigração russófona desde 2001, no entanto, os números exatos não são conhecidos (Vorobyeva; Aleshkovski; Grebenyuk, 2018).

Considerando essa heterogeneidade étnica, nacional, religiosa e política das populações pós-soviéticas, a noção da russofonia permite dar contorno, mesmo que imperfeito, para o fenômeno emigratório surgido após 1991, no qual o idioma russo se tornou um denominador comum. Ryazantsev e Grebeniuk (2014: 9) apontam que "a língua russa é um instrumento social efetivo que promove a coesão dos migrantes no exterior" por meio da criação e manutenção de espaços sociais coletivos russófonos na internet e presenciais. Ela permite aos seus portadores a capacidade de circular por entre diferentes "espaços linguísticos e culturais", preservando as suas diferenças étnicas e nacionais ao mesmo tempo que se beneficiando de redes sociais criadas na base do idioma comum. 
A migração russófona compreende os representantes dos três grupos descritos acima. Embora as estimativas numéricas sejam dificultadas pela extrema heterogeneidade dessa população, as estatísticas referentes à emigração dos cidadãos da Rússia são mais acessíveis: esse grupo é mais numeroso.

Segundo os dados oficiais de Rosstat (Serviço Federal de Estatística Estatal da Rússia), provavelmente subestimados em 3-4 vezes, no período de 1993 a 2016 mais de 4 milhões de cidadãos russos deixaram o país natal (Vorobyeva; Aleshkovski; Grebenyuk, 2018). Em 1993, emigraram quase 500 mil russos, depois os números foram diminuindo gradativamente até chegar em 32 mil em 2009. A partir de 2012 a quantidade de emigrantes aumentou novamente, chegando a 313 mil em 2016. Segundo o último relatório da Organização Internacional para as Migrações, atualmente, a Rússia está em quarto lugar no mundo pelo número total de seus nacionais residentes no exterior, avaliado em mais de 10 milhões (IOM, 2019: 26).

Quanto ao número de emigrantes, entre os países ex-soviéticos, se destacam a Ucrânia (8o lugar do mundo, com mais de 5 milhões) e o Cazaquistão (15o lugar do mundo, com mais de 4 milhões) (IOM, 2019: 26). Os motivos da emigração incluem a busca por melhores condições econômicas, status social e estabilidade (Popkov; Popkova, 2020; Vorobyeva; Aleshkovski; Grebenyuk, 2018). As principais ocupações de migrantes russos desde 2001 são o empreendedorismo e a pesquisa em centros universitários; também se destaca o fenômeno da migração matrimonial (Vorobyeva; Aleshkovski; Grebenyuk, 2018).

\section{MIGRAÇÃO RUSSÓFONA NO BRASIL NOS SÉCULOS XIX E XX: UM BREVE HISTÓRICO}

A imigração russófona ao Brasil pode ser analisada a partir de quatro períodos. $\mathrm{O}$ primeiro, na passagem do século XIX ao XX, foi o período da vinda dos imigrantes do Império Russo (Bytsenko, 2006; Blay, 2013). Ele inclui duas levas migratórias de natureza distinta: uma de alemães russos e das minorias religiosas, a imigração predominantemente rural; e outra dos judeus russos da região Sudeste do Império que fugiam dos pogroms e da discriminação, a imigração predominantemente urbana.

O segundo período se estende desde a revolução bolchevique de 1917 e da guerra civil russa até a Segunda Guerra Mundial. Em 1921, o Brasil recebeu cerca de 1000 refugiados apátridas, ex-soldados e oficiais do exército branco contrarrevolucionário (Ruseishvili, 2016). Entre 1920 e 1927, chegaram cerca de 29 mil camponeses provenientes da Bessarábia romena, predominantemente russófonos (Ruseishvili, no prelo; Cocicov, 2005). Ao longo da década de 1930, diversos grupos de russos, ucranianos, letos e outros migrantes, muitos dos quais russófonos, vieram ao Brasil da Europa Oriental, afetada pela revolução russa, pelas tensões geopolíticas e pela crise econômica (Ruseishvili, 2016).

O terceiro período da vinda de migrantes russófonos acontece após a Segunda Guerra Mundial. Nos atos de registro migratório dessa época há pouca precisão, já que muitos deles entram como apátridas ou se dissolvem nas estatísticas de diversos grupos nacionais, polo- 
neses, iugoslavos, húngaros, etc. Nessa leva migratória se destacam os refugiados russos da China, cujo número pode chegar a 9 mil pessoas (Ruseishvili, 2018). Eles se estabeleciam em grandes centros urbanos, principalmente em São Paulo e no Rio de Janeiro.

O quarto período é o fim da URSS e a vinda dos cidadãos da ex-URSS. Até o ano 2000, o número de russófonos que imigravam para a América Latina não chamava muita atenção, os destinos principais eram os EUA, Israel e Alemanha (Vorobyeva; Aleshkovski; Grebenyuk, 2018). Contudo, nas últimas décadas a América Latina surge como um destino para diversos grupos de migrantes do espaço pós-soviético. Assim como nas épocas anteriores, essa população é heterogênea em sua condição socioeconômica, em seus projetos migratórios e em modos de incorporação no país de instalação.

Essa heterogeneidade parece indicar uma quarta dinâmica migratória para além dos fluxos Sul-Norte, Sul-Sul e Norte-Sul: uma dinâmica Leste-Sul, que incorpora tanto as características das migrações de "estilo de vida" Norte-Sul, quanto às migrações econômicas, de trânsito e de refúgio Sul-Sul e Sul-Norte. Vale analisar o espaço pós-soviético pela perspectiva de processos pós-coloniais, marcados pela história do Império Russo e Soviético, um "império subalterno" (Morozov, 2014) que ao mesmo tempo que colonizava os povos da Sibéria, Cáucaso e Ásia Central, imitando o colonialismo europeu, era considerado inferior pelos grandes Impérios europeus. No modelo do sistema de Três Mundos (Koplatadze, 2019), embora polêmico, o espaço pós-soviético, o Segundo Mundo, seguia compreendido sobretudo por meio de seu não pertencimento tanto ao "mundo" colonizador e capitalista ocidental, quanto ao "mundo" colonizado e em desenvolvimento. Nesse sentido, tanto os projetos migratórios quanto os modos de inserção dos migrantes russófonos nos países do Sul Global reproduzem essas dinâmicas ambíguas do pós-soviético como simultaneamente hegemônico e subalterno, desenvolvido e em desenvolvimento, o que se reflete no perfil heterogêneo desses migrantes no Brasil.

\section{A PRESENÇA DE RUSSÓFONOS NO BRASIL CONTEMPORÂNEO}

Diante da falta de dados consolidados sobre os cidadãos russos residentes no Brasil nos órgãos estatísticos russos, recorremos aos dados produzidos no âmbito de pesquisas brasileiras. O Banco Interativo do Observatório das Migrações em São Paulo da Universidade Estadual de Campinas é uma ferramenta recente e atualizada que permite visualizar os registros administrativos de migrantes na Polícia Federal brasileira (SISMIGRA, Banco Interativo, 2020). A pesquisa referente aos imigrantes da Rússia mostra que de 2000 até outubro de 2020, 7031 pessoas solicitaram o registro no país, 1952 delas no estado de São Paulo, sendo na cidade de São Paulo 921. Desse universo, a maioria, 5184 (73,7 \%), possuía vistos temporários, e 1831 vistos permanente e residente $(26 \%)$ Os números de imigrantes russos podem ser visualizados ano por ano na Tabela 1. O aumento do fluxo migratório dos russos que chegam ao Brasil a partir de 2011 corresponde às tendências gerais de aumento do número de russos que deixam o país natal abordadas anteriormente (Vorobyeva; Aleshkovski; Grebenyuk, 2018). Além disso, em 2010 entrou em vigor o acordo de isenção de vistos de curta duração entre a Rússia e o Brasil o que facilitou a 
vinda de cidadãos russos. A partir de 2016, decresce o número de registros novos de imigrantes russos no Brasil. É provável que essa diminuição seja relacionada à grave crise política, econômica e social que o Brasil atravessa.

Tabela 1 - Números de pedidos de cadastro feitos por imigrantes russos na Polícia Federal do Brasil, organizados por ano.

\begin{tabular}{|c|c|c|c|c|c|c|c|}
\hline Ano & $\begin{array}{c}\text { Imigrantes } \\
\text { russos }\end{array}$ & Ano & $\begin{array}{c}\text { Imigrantes } \\
\text { russos }\end{array}$ & Ano & $\begin{array}{c}\text { Imigrantes } \\
\text { russos }\end{array}$ & Ano & $\begin{array}{c}\text { Imigrantes } \\
\text { russos }\end{array}$ \\
\hline 2000 & 261 & 2005 & 199 & 2010 & 340 & 2015 & 572 \\
\hline 2001 & 123 & 2006 & 211 & 2011 & 566 & 2016 & 524 \\
\hline 2002 & 109 & 2007 & 244 & 2012 & 633 & 2017 & 421 \\
\hline 2003 & 155 & 2008 & 345 & 2013 & 565 & 2018 & 341 \\
\hline 2004 & 129 & 2009 & 361 & 2014 & 500 & 2019 & 377 \\
\hline
\end{tabular}

Fonte: SISMIGRA, Banco Interativo do Observatório das Migrações em São Paulo, 2020.

Referente aos imigrantes de outros países onde a maioria da população é russófona (Zhou; Koloda, 2019), do ano 2000 até os tempos atuais solicitaram o registro no Brasil 4261 imigrantes da Ucrânia, 548 da Cazaquistão e 265 da Belarus. Além disso, há imigrantes e refugiados russófonos de outros países do espaço pós-soviético e, também, imigrantes que não solicitaram o cadastro na Polícia Federal, principalmente os que entraram como turistas e permanecem no país em situação migratória irregular.

\section{PERFIS DE MIGRANTES RUSSÓFONOS NO BRASIL CONTEMPORÂNEO}

A ferramenta do Banco Interativo do Observatório das Migrações em São Paulo permite visualizar uma série de informações sobre os migrantes registrados no SISMIGRA (2020). Entre os imigrantes russos, a maioria (93\%) estão na faixa etária de 15 a 59 anos, dois terços são homens, mais da metade são casados (Tabela 2). O Banco Interativo permite também visualizar as faixas etárias de cinco em cinco anos, separadamente para homens e mulheres. Nessa análise, podemos ver que $71 \%$ das mulheres russas que se regularizam no Brasil estão na faixa etária de 20 a 34 anos, enquanto para os homens nessa faixa etária estão somente $44 \%$. Os homens russos são bem representados em todas as faixas etárias de 20 a 54 anos, com o pico entre 25 e 39 anos. Com os documentos de permanência/residência estão $26 \%$ dos imigrantes.

Tabela 2 - Dados demográficos referentes aos imigrantes russos e ucranianos que solicitaram o cadastro na Polícia Federal do Brasil.

\begin{tabular}{|c|c|c|c|c|}
\hline & $\begin{array}{c}\text { Imigrantes } \\
\text { russos no } \\
\text { Brasil todo }\end{array}$ & $\begin{array}{c}\text { Imigrantes } \\
\text { russos no } \\
\text { estado de São } \\
\text { Paulo }\end{array}$ & $\begin{array}{c}\text { Imigrantes } \\
\text { ucranianos no } \\
\text { Brasil todo }\end{array}$ & $\begin{array}{c}\text { Imigrantes } \\
\text { ucranianos no } \\
\text { estado de São } \\
\text { Paulo }\end{array}$ \\
\hline $\begin{array}{l}\text { Número de } \\
\text { imigrantes }\end{array}$ & 7031 & 1952 & 4261 & 914 \\
\hline
\end{tabular}




\begin{tabular}{|c|c|c|c|c|}
\hline Homens & $68,3 \%$ & $56,1 \%$ & 83,8 & $69,3 \%$ \\
\hline Mulheres & $31,7 \%$ & $43,9 \%$ & 16,2 & $30,7 \%$ \\
\hline Casados & $60 \%$ & $55 \%$ & $65 \%$ & $57 \%$ \\
\hline Solteiros & $34 \%$ & $39 \%$ & $30 \%$ & $38 \%$ \\
\hline $\begin{array}{c}\text { Permanentes e } \\
\text { residentes }\end{array}$ & $26 \%$ & $31 \%$ & $15 \%$ & $23 \%$ \\
\hline
\end{tabular}

Fonte: SISMIGRA, Banco Interativo do Observatório das Migrações em São Paulo, 2020

O Banco Interativo também oferece as informações sobre a ocupação econômica desses migrantes, consolidadas a partir da indicação que o próprio solicitante realiza no ato do preenchimento do formulário da Polícia Federal. Entre os cidadãos russos, a categoria mais representada é dos trabalhadores marítimos e similar (2 921), o que explica os números elevados de homens e dos indivíduos com visto temporário. Em seguida, são estudantes (714) e ocupações não classificadas ou não identificadas (807 no total). Vale destacar que uma das estratégias de permanência no país, muito usada pelos migrantes russófonos, é a obtenção inicial da autorização de residência temporária para estudantes (sobretudo, nas escolas de idiomas) para a sua posterior conversão em residência definitiva por tempo indeterminado (com base em casamento ou prole brasileira, por exemplo). A esses seguem os professores (367 russos), engenheiros (290), lides do lar (222) e diretores, gerentes e proprietários (165). De acordo com esses dados, o perfil socioprofissional dos migrantes russos no Brasil corresponde a uma migração qualificada, porém, esses números não nos oferecem uma imagem dinâmica de mudança de ocupação ao longo da residência no Brasil, o que poderia indicar dinâmicas de ascensão ou declínio social.

Os perfis de imigrantes ucranianos são parecidos com os russos (Tabela 2), e mesmo a distribuição desigual de homens e mulheres em faixas etárias e a lista de ocupações principais com destaque aos professores e engenheiros seguem um padrão similar (SISMIGRA, Banco Interativo, 2020).

A cidade de Florianópolis apresenta um perfil diferente das médias observadas no Brasil: com o acumulado de somente 170 imigrantes russos registrados desde 2000, o fluxo cresceu nos últimos anos e apenas em 2019 chegou a apresentar 41 indivíduos. De encontro com as médias descritas na Tabela 2, em Florianópolis mulheres representam $60 \%$ dos imigrantes russos, um terço delas na faixa etária de 25-29 anos (SISMIGRA, Banco Interativo, 2020). Além disso, 80\% dos imigrantes são permanentes ou residentes, os temporários são a minoria. Supõe-se que esses dados refletem o trabalho das agências russófonas que atendem os casais russos em busca de um local onde após dar à luz seus filhos possam adquirir a cidadania do país e posteriormente proporcionar a naturalização também aos pais (o chamado "turismo de parto"): esses empreendedores russófonos transnacionais, localizados na capital catarinense mas voltados ao público do espaço pós-soviético, produzem uma imagem de Florianópolis como uma cidade quase europeia, com uma boa qualidade de vida e um bom sistema de saúde pública (Maciel, 2020a). O perfil atípico de migrantes russos que, em alguns casos, vão embora depois de dar à luz em Florianópolis e não voltam na UBS com o bebê, chegou a gerar suspeita de tráfico de 
crianças por famílias russas (Maciel, 2020b). Em 2019, um bebê de dois dias foi retirado dos pais e precisou passar alguns dias no abrigo. No caso, a suspeita era alimentada pelo perfil migratório dos pais da criança que não possuíam residência definitiva e não permaneciam no local de residência indicado na ficha médica. Na realidade, o projeto do casal foi de voltar ao seu país de origem logo após o nascimento do filho com possibilidade de retornar ao Brasil no futuro quando precisariam da cidadania brasileira.

\section{IDIOMA, CELPE-BRAS E O PROJETO DE NATURALIZAÇÃO}

O nosso grupo de pesquisa tem trabalhado na criação de um banco de dados que inclui fichas detalhadas e gravações de áudio e vídeo de 40 russófonos que moram em São Paulo (Smirnova Henriques et al., no prelo). O banco foi criado com a intenção de caracterizar o sotaque russo em português brasileiro e a expressões de emoções em bilíngues, no entanto, ele também contém os dados demográficos e sociolinguísticos. Nesse banco, há dados obtidos de 30 mulheres e 10 homens, 28 deles nascidos na Rússia; 18 deles mudaram para o Brasil por causa de trabalho ou estudo, e 22 por motivos familiares, principalmente a criação de família com brasileiros. Analisando as fichas dos participantes do banco, observamos que somente 15 dos 40 migrantes relataram estudar português antes de mudar para o Brasil, 9 deles autodidatas (Smirnova Henriques et al., no prelo). Quando aplicamos um questionário on-line mais detalhado a 97 migrantes russófonos que moravam/moraram em diferentes lugares do Brasil, 58\% deles relataram estudar português somente depois de mudar para o Brasil e sozinhos (Smirnova Henriques et al., 2019). Somente 7\% ingressaram no Brasil numa escola de idiomas.

Na Rússia há poucas oportunidades para aprender português brasileiro como língua estrangeira, entre elas se destacam os Centros Culturais Brasileiros em Moscou e São Petersburgo (Arefiev, 2019). O português continental é ensinado somente em 9 de 965 universidades russas; somente 15 mil pessoas de toda a população russa de 147 milhões se declaram proficientes em português. Os professores de português como língua estrangeira em Portugal também relatam que os migrantes da Europa do Leste frequentemente chegam no país sem ter estudado português antes (Head; Semenova-Head, 2010).

No entanto, no Brasil também há poucas oportunidades para receber uma instrução formal em português brasileiro como língua estrangeira. Esse campo no Brasil é novo, faltam os materiais didáticos e cursos de formação para professores: muitos cursos de português brasileiro como língua estrangeira para recém-chegados são oferecidos por ONGs, onde os voluntários não têm a formação específica na área (ACNUR, 2019; Adam; Fernandes Massuci; Furtoso, 2009; Amado, 2013; Farneda, 2019). Mesmo nos cursos de extensão para migrantes nas universidades nem sempre os professores tiveram a oportunidade de cursar a graduação em ensino de português como língua estrangeira: esses cursos de graduação são recentes e poucos, por muito tempo a Universidade de Brasília foi a única que oferecia esta modalidade (Farneda, 2019). As dificuldades no acesso de migrantes à instrução formal em português brasileiro são confirmadas pelos resultados da recente pesquisa feita pelo Alto Comissariado das Nações Unidas para os Refugiados 
(ACNUR): 46\% dos refugiados dos países que não pertencem ao mundo da língua portuguesa não frequentaram nenhum curso de português no Brasil (ACNUR, 2019).

No nosso banco de dados de russófonos de São Paulo, dois participantes de 40 mencionaram o curso para estrangeiros na FFLCH-USP (Faculdade de Filosofia, Letras e Ciências Humanas da Universidade de São Paulo) e uma, graduada na Rússia, relatou entrar na EJA (Educação de Jovens e Adultos) (Smirnova Henriques et al., no prelo). Mais uma pessoa estudou português na FAAP (Fundação Armando Alvares Penteado), no entanto, destacou como ponto negativo que o valor do curso era maior do que um salário mínimo.

Até 2018, aprender português era uma escolha pessoal de cada migrante. Porém, o cenário mudou em 2018 quando o Brasil passou a exigir o certificado de proficiência Celpe-Bras (ou um meio alternativo de comprovação de proficiência, como um diploma de uma instituição de ensino superior brasileira) para a naturalização dos migrantes (Brasil, 2018). Inicialmente, o Celpe-Bras foi desenvolvido como uma prova para estrangeiros que desejam ingressar em uma universidade brasileira, por isso, além de uma prova oral de 20 minutos, ele inclui quatro redações que precisam ser escritas em três horas baseadas em um áudio, um vídeo e dois artigos de jornal/revista, usando o estilo acadêmico (Péret Dell'Isola, 2014). Muitos russófonos que aprenderam em primeiro lugar o português falado e, mesmo sendo fluentes nessa modalidade, nunca tiveram contato com o idioma acadêmico (por exemplo, mulheres que vieram para o Brasil pela reunião familiar e logo tiveram filhos) não conseguem passar nesta prova sem um curso preparatório específico e muita prática de leitura sobre os diversos assuntos. No entanto, ainda há poucos professores preparados e cursos disponíveis, e ainda menos acessíveis financeiramente e numa modalidade de ensino que possa acolher mulheres com filhos pequenos, um dos grupos que mais deseja a cidadania brasileira.

A partir da análise das entrevistas coletadas para a construção do nosso banco de russófonos de São Paulo (Smirnova Henriques et al., no prelo), observamos que, para muitos russófonos, a naturalização brasileira é um ponto central em seu projeto migratório. Uma das importantes vantagens de ter o passaporte brasileiro é a facilitação de viagens para outros países: os cidadãos russos até agora precisam de visto para entrar no espaço Schengen e na maioria dos países europeus. Os nossos interlocutores relatam que as viagens internacionais em família frequentemente se transformam em um pesadelo burocrático: enquanto os membros da família com passaporte brasileiro viajam sem grandes restrições, os membros com passaportes russos e outros pós-soviéticos precisam enfrentar processos de obtenção de vistos, custosos em tempo, esforços e finanças. Nesses momentos, os indivíduos ressentem o lugar subalterno que o seu país ocupa no regime internacional de controle migratório. No ranking internacional de passaportes baseado na quantidade de países que o seu portador pode acessar sem visto, o passaporte brasileiro ocupa $18^{\circ}$ lugar, com 170 países sem exigência de visto, enquanto o russo está em $48^{\mathrm{a}}$ posição, com 117 países livres de vistos (Henley \& Partners, 2020). Mesmo para os países que exigem o visto quanto dos russos, tanto dos brasileiros, o tratamento recebido pelos primeiros pode diferir muito do tratamento recebido pelos segundos, no que tange, por 
exemplo, à duração de vistos recebidos. No caso dos EUA, a praxe para brasileiros é emitir visto de 10 anos, e para russos, de 3 anos, mesmo se o casal russo-brasileiro viaja junto.

Nesse projeto de naturalização, a exigência do certificado Celpe-Bras dificultou significativamente o processo. Não somente a prova em si é difícil, mas também o acesso a ela: Anunciação e Camargo (2019) veem o Celpe-Bras como um instrumento gatekeeper linguístico no caminho da aquisição de cidadania por migrantes. A prova de Celpe-Bras acontece não mais que duas vezes por ano, a inscrição dura poucos dias, o sistema de inscrição falha frequentemente e as vagas acabam rapidamente. Para residentes de São Paulo, os locais mais próximos para realizar a prova são: São Bernardo do Campo e Campinas. Uma das nossas interlocutoras relatou não ter conseguido se inscrever nos locais próximos a São Paulo em 2019, por falta de vagas, e por isso se inscreveu em Porto Alegre. No dia da prova, uma tempestade impediu o avião dela pousar em Porto Alegre e ela voltou para São Paulo para aguardar mais seis meses até a próxima abertura de inscrição. Em 2020, dezenas de postos aplicadores de Celpe-Bras, como Universidade de Brasília, Unicamp, Universidade Metodista em São Bernardo do Campo, UFRJ e muitos outros, cancelaram a única edição da prova de 2020 em razão da pandemia da COVID-19 (NEPPE, 2020; UNICAMP, 2020). Mesmo na epidemia, a Polícia Federal continua o atendimento de migrantes, inclusive para a naturalização, mas obter o certificado de Celpe-Bras em 2020 não parece ser muito fácil.

\section{CONSIDERAÇÕES FINAIS}

Neste trabalho, discutimos as condições na Rússia e em outros países do espaço pós-soviético que estimulam os crescentes fluxos migratórios, apresentamos os perfis de imigrantes russófonos no Brasil contemporâneo e descrevemos como o acesso restrito à instrução formal em língua portuguesa, necessária para passar na prova de proficiência em português brasileiro Celpe-Bras, dificulta o caminho desses migrantes à naturalização.

Ressaltamos que as migrações pós-soviéticas representam um objeto de estudos imerecidamente ignorado pelos estudos migratórios no Brasil. Como mencionado, a Rússia é um dos cinco maiores produtores de migrantes internacionais no mundo; ela também é o quarto país no mundo que mais recebe migrantes internacionais, principalmente do espaço pós-soviético (IOM, 2020: 26). Essa característica dupla de origem e destino dos migrantes internacionais reflete a posição ambígua do país na geopolítica internacional contemporânea e é resultado do passado complexo de um "império subalterno". Ao mesmo tempo, outros países pós-soviéticos que integram o espaço transnacional conectado por meio do compartilhamento do idioma russo, que definimos como "espaço social russófono", também tem se destacado no mapa das migrações internacionais. A Ucrânia, por exemplo, tem gerado um fluxo considerável de deslocados forçados internos e internacionais desde o início do conflito armado nos territórios no Leste do país em 2014. Em 2018, a Rússia e a Ucrânia juntas produziram a maior população de deslocados forçados na Europa, 61.000 e 93.000, respectivamente (IOM, 2020: 90). No Brasil, de 2014 a 
2019 o Comitê Nacional para os Refugiados (CONARE) recebeu 59 solicitações de refúgio dos cidadãos ucranianos; para cidadãos russos, há 37 solicitações registradas a partir de 2016 (CONARE, 2020).

Quando analisamos características demográficas dos migrantes russófonos no Brasil, percebemos que embora se trate de uma migração qualificada, os projetos migratórios contemplam a aquisição rápida da cidadania brasileira para compensar o baixo status do passaporte russo no regime internacional de controle migratório. Para esse fim, diversas estratégias e modos da mobilidade internacional são empregados: turismo de parto, conversão de visto temporário em visto permanente, matrimônio, prorrogação da validade do visto de turista por meio de saídas e entradas consecutivas do território brasileiro para os países vizinhos e também a permanência na irregularidade no aguardo da anistia. Pensar nessas jornadas, projetos e estratégias migratórias pela lente de uma dinâmica migratória que contemple o movimento do Leste ao Sul Global poderia inaugurar novas agendas de pesquisa e abrir novos caminhos analíticos para a compreensão do regime global de migrações contemporâneas.

\section{AGRADECIMENTOS}

Dra. Smirnova Henriques é bolsista de PNPD/CAPES (Programa Nacional de Pós-Doutorado da Coordenação de Aperfeiçoamento de Pessoal de Nível Superior). Nossos agradecimentos à Profa. Dra. Sandra Madureira (PUC-SP) pela revisão do manuscrito.

\section{REFERÊNCIAS BIBLIOGRÁFICAS}

ACNUR (2019). Perfil socioeconômico dos refugiados no Brasil. https://www.acnur.org/ portugues/wp-content/uploads/2019/07/Pesquisa-Perfil-Socioecon \%C3\%B4mico-Refugiados-ACNUR.pdf. Consultado em: 19/10/2020.

ADAM, Andreia Ros Segundo; FERNANDES MASSUCI, Camila; FURTOSO, Viviane Bagio (2009). Formação de professores de PFOL na graduação: relato de experiência. In: FURTOSO, V. B. (Org.) Formação de professores de Português para Falantes de Outras Linguas. Londrina: Eduel, 65-76.

AMADO, Rosane de Sá (2013). O ensino de português como língua de acolhimento para refugiados. In: Revista da Sociedade Internacional Português Língua Estrangeira - SIPLE, v. 4, n. 2, p. 1-6.

ANUNCIAÇÃO, Renata; CAMARGO, Helena (2019). O exame do Celpe-Bras como política de gatekeeping para naturalização no Brasil. Muiraquitã - Revista de Letras e Humanidades, v. 7, n. 2, p. 10-22.

AREFIEV, Aleksandr (2019). Sotrudnichestvo Rossii i Portugalii v oblasti obrazovaniya i vzaimnoe izuchenie iazykov [Cooperation between Russia and Portugal in the education field and mutual learning of languages]. In: NIKUNLASSI, Ahti; PROTASSOVA, Ekaterina (Eds.). Slavica Helsingiensia 52. Russian Linguage in the Multilingual World. Helsinki, University of Helsinki, p. 123-133.

BAENINGER, Rosana et al. (Org) (2018). Migrações Sul-Sul. Campinas: NEPO/ Unicamp. 
BLAY, Eva Alterman (2013). O Brasil como destino. Raízes da imigração judaica contemporânea para São Paulo. São Paulo: Editora UNESP.

BRASIL (2018). Portaria Interministerial $n^{\circ} 11$, de 3 de maio de 2018. Dispõe sobre os procedimentos para solicitação de naturalização, de igualdade de direitos, de perda, de reaquisição de nacionalidade brasileira e de revogação da decisão de perda da nacionalidade brasileira e dá outras providências. Diário Oficial da União, Brasília, DF, de 4 de maio de 2018. Seção 1, ed. 85, p. 46.

BYTSENKO, Anastassia (2006). Imigração da Rússia para o Brasil no início do século XX. Visões do paraíso e do inferno. 130 f. 2006. Dissertação (Mestrado em Letras) - Faculdade de Filosofia, Letras e Ciências Humanas, Universidade de São Paulo, São Paulo. https://www.teses.usp.br/teses/disponiveis/8/8155/tde-12112007-132926/pt-br.php

COCICOV, Jorge (2005). Imigração no Brasil: Búlgaros e gagaúzos bessarabianos. Legis Summa: São Paulo.

COMISSÃO ELEITORAL CENTRAL DA FEDERAÇÃO RUSSA (2020). Vybory, referendumy $i$ inye formy prjamogo voleizjavlenija [Eleições, referendos e outras formas de manifestações de escolhas]. http://www.izbirkom.ru/region/izbirkom. Consultado em: 04/07/2020.

CONARE (2020). 1990 a 2019, solicitações de reconhecimento da condição de refugiado. Disponível em: http://dados.mj.gov.br/dataset/comite-nacional-para-os-refugiados/ resource/4a82b3c6-53d4-42d6-99f5-09183cec4e30. Consultado em: 20/10/2020.

FARNEDA, Eliete Sampaio (2019). Português língua de acolhimento - cursos de extensão e capacitação para professores de português língua materna: abordagens e práticas. In: MAIA, Francisca Paula Soares; MENDES, Regina Maria Gonçalves (Eds.). Ensino e Aprendizagem de Línguas Adicionais em Foco. Roosevelt, NJ: Boavista Press, p. 53-64.

FAUSTO, Boris (1991). Historiografia de Imigração para São Paulo. São Paulo: Editora Sumaré.

HEAD, Brian Frankilin; SEMENOVA-HEAD, Larissa (2010). Problemas na aprendizagem da pronúncia portuguesa entre falantes adultos de russo. Cadernos de Comunicação e Linguagem, v. 2, p. 13-33. https://bdigital.ufp.pt/handle/10284/2957.

HENLEY; PARTNERS (2020). Passport Index. https://www.henleypassportindex.com/ passport. Consultado em: 5/10/2020.

IOM - INTERNATIONAL ORGANIZATION FOR MIGRATION (2019). World Migration Report 2020. MCAULIFFE, Marie; KHADRIA, Binod (Eds.). Geneva, IOM, 2019. https://publications.iom.int/books/world-migration-report-2020.

KOPLATADZE, Tamar (2019). Theorising Russian postcolonial studies. Postcolonial Studies, vol. 22, n. 4, p. 469-489.

MACIEL, Roelton (2020a). Os motivos que levam casais russos a darem à luz bebês em Santa Catarina. NSC Total, 23 de fevereiro de 2019. https:/www.nsctotal.com.br/noticias/os-motivos-que-levam-casais-russos-a-darem-a-luz-bebes-em-santa-catarina. Consultado em: 19/10/2020.

MACIEL, Roelton (2020b). MP questiona destino de bebês russos nascidos em Florianópolis. NSC Total, 19 de fevereiro de 2019. https://www.nsctotal.com.br/noticias/mp-ques- 
tiona-destino-de-bebes-russos-nascidos-em-florianopolis. Consultado em: 19/10/2020.

MOROZOV, Viatcheslav (2014). Russia's Postcolonial Identity: A Subaltern Empire in a Eurocentric World. Basingstoke: Palgrave Macmillan.

NEPPE (2020). Ceple-Bras-2020: cancelamento de participação da Universidade de Brasilia. http://www.neppe.unb.br/br/cursos/79-cursos/275-celpe-bras-2020-cancelamento-da-participacao-da-universidade-de-brasilia. Acessso em 20 de outubro de 2020.

PANARIN, Serguei (1999). Russkojazychnye u vneshnih granits Rossii: vyzovy i otvety (na primere Kazahstana) [Russophones near to the external borders of Russia: challenges and answers (on the exemple of Kazakhstan)]. Diaspory, n. 2-3, p. 136-168. http://www. archipelag.ru/ru mir/rm-diaspor/russ/russian-speaking/

PÉRET DELL'ISOLA, Regina Lúcia (2014). Exame de Proficiência Celpe - Bras em foco. Campinas: Pontes Editores.

POPKOV, Viacheslav D.; POPKOVA, Ekaterina A. (2020) Russkojazychnye gruppy v Germanii: migracionnaja motivacija [Russian-Speaking Groups in Germany: Motivation for Migration]. Vestnik Volgogradskogo gosudarstvennogo universiteta. Seriya 4. Istoriya. Regionovedenie. Mezhdunarodnye otnosheniya, v. 25, n. 1, p. 229-240. https://doi. org/10.15688/jvolsu4.2020.1.19.

RUSEISHVILI, Svetlana (2016). Ser russo em São Paulo. Os imigrantes russos e a reformulação de identidade após a Revolução Bolchevique de 1917. 383 f. Tese (Doutorado em Sociologia) - Faculdade de Filosofia, Letras e Ciências Humanas, Universidade de São Paulo, São Paulo. https://teses.usp.br/teses/disponiveis/8/8132/tde-13022017-124015/pt-br.php.

RUSEISHVILI, Svetlana (2018). Perfil sociodemográfico e distribuição territorial dos russos em São Paulo: deslocados de guerra da Europa e refugiados da China após a Segunda Guerra Mundial. Revista Brasileira de Estudos de População, vol. 35, n. 2, p. 1-20.

RUSEISHVILI, Svetlana (no prelo). Entre o campo e a cidade: a mobilidade dos imigrantes bessarábios em São Paulo na primeira metade do século XX. In: Truzzi, Oswaldo (Org.). Migrações Internacionais no Interior Paulista: contexto, trajetórias e associativismo (1880-1950). São Carlo's: EdUFSCar.

RYAZANTSEV, Serguei; GREBENIUK, Aleksandr (2014). "Nashi” za granitsei: russkie, rossiane, russkogovoriashie, sootechestvenniki [Ours abroad: Russians, Russian-speakers, Compatriots]. Moscou, ISPI RAN.

SEYFERTH, Giralda (2014). A Imigração no Brasil: comentários sobre a contribuição das Ciências Sociais. BIB - Revista Brasileira de Informação Biobliográfica em Ciências Sociais. Rio de Janeiro, v. 57, p. 7-47.

SISMIGRA, 2000/2020. (2020) Departamento da Polícia Federal - Ministério da Justiça e Segurança Pública do Brasil/OBMigra. Tabulações: Banco Interativo do Observatório das Migrações em São Paulo - NEPOUNICAMP - CNPq/MPT. https://www.nepo.unicamp.br/observatorio/bancointerativo/. Consultado em: 13/10/2020.

SMIRNOVA HENRIQUES, Anna et al. (2019). The perception of Brazilian Portuguese open and close mid vowels by native Russian speakers. JoSS, v. 8, n. 2, p. 59-84.

SMIRNOVA HENRIQUES, Anna et al. (no prelo). Russian immigrants in Brazil: to understand, to be understood. Cadernos de Linguística. 
TERTRI, David (2017). Russkij vopros v postsovetskij period [The Russian question in the post-soviet period]. Vestnik Sankt-Peterburgskogo universiteta. Istorija. v. 62, n. 1, p. 43-56. http://vestnik.spbu.ru/html17/s02/s02v1/04.pdf.

UNICAMP (2020). A Unicamp cancelou a aplicação do Celpe-Bras em 2020. https:// www2.iel.unicamp.br/celpebrasunicamp/. Consultado em: 20/10/2020.

VOROBYEVA, Olga; ALESHKOVSKI, Ivan; GREBENYUK, Aleksandr. (2018). Russian emigration at the turn of the 21 st century. Filosofija. Sociologija, v. 29, n. 2, p. 107118, 2018. https://doi.org/10.6001/fil-soc.v29i2.3706.

ZHOU, Xie; KOLODA, Svetlana (2019). K voprosu ob ispol'zovanii termina «russkojazychnye (russkogovorjashhie) strany» v gumanitarnyh issledovanijah [On the use of the term «Russian-speaking countries» in the humanitarian studies]. Мир русскоговорящих стран. Regionovedenie, n. 1, p. 36-42, 2019.

Recebido em 20/10/2020 - Aprovado em 03/11/2020 